\title{
Distributed Multiple Tuned Mass Dampers for Wind Vibration Response Control of High-Rise Building
}

\author{
Said Elias and Vasant Matsagar \\ Department of Civil Engineering, Indian Institute of Technology (IIT) Delhi, Hauz Khas, New Delhi 110 016, India \\ Correspondence should be addressed to Said Elias; said.elias@civil.iitd.ac.in
}

Received 31 August 2014; Accepted 25 October 2014; Published 23 November 2014

Academic Editor: Radhey S. Jangid

Copyright ( 92014 S. Elias and V. Matsagar. This is an open access article distributed under the Creative Commons Attribution License, which permits unrestricted use, distribution, and reproduction in any medium, provided the original work is properly cited.

\begin{abstract}
Multiple tuned mass dampers (MTMDs) distributed along height of a high-rise building are investigated for their effectiveness in vibration response control. A 76-storey benchmark building is modeled as shear type structure with a lateral degree of freedom at each floor, and tuned mass dampers (TMDs) are installed at top/different floors. Suitable locations for installing the TMDs and their tuning frequencies are identified based, respectively, on the mode shapes and frequencies of the uncontrolled and controlled buildings. Multimode control strategy has been adopted, wherein each TMD is placed where the mode shape amplitude of the building is the largest or large in the particular mode being controlled and tuned with the corresponding modal frequency. Newmark's method is used to solve the governing equations of motion for the structure. The performance of the distributed MTMDs (d-MTMDs) is compared with single tuned mass damper (STMD) and all the MTMDs placed at top floor. The variations of top floor acceleration and displacement under wind loads are computed to study the effectiveness of the MTMDs in vibration control of the high-rise building. It is concluded that the d-MTMDs are more effective to control wind induced vibration than the STMD and the MTMDs placed at top floor.
\end{abstract}

\section{Introduction}

The buildings are built taller, lighter, and slender as per modern world requirement, with the use of advanced technology, knowledge of new materials, and analysis software, which have assured safe constructions and comfort to human life. In the tall buildings, wind and earthquake borne vibrations are typically controlled by the use of tuned mass dampers (TMDs). The well-established concept of TMDs was originated since an attempt made by Frahm [1]. Much later, Randall et al. [2] have computationally investigated optimal linear vibration absorber for linear damped primary system. The studies on optimum control of absorbers continued over the years and different approaches have been proposed by the researchers. Tsai and Lin [3] concluded that the optimum absorber can reduce the peak response for input frequencies near the natural frequency of the main system. They also showed that, for lower input frequencies, response amplitudes may amplify. Moreover, they concluded that when the main system had high damping, vibration absorber was less effective in reducing the system response. Soong and Dargush [4] concluded that the TMDs are most effective when the first mode contribution to the response is dominant. This is generally the case for tall, slender structural systems.

Multiple tuned mass dampers (MTMDs) have also been investigated widely for their effectiveness in vibration control. Iwanami and Seto [5] had shown that two TMDs are more effective than single TMD and, later, $\mathrm{Xu}$ and Igusa [6] proposed the use of multiple suboscillators with closely spaced frequencies. Their study confirmed that the optimally designed MTMDs are more effective and robust than an optimally designed single TMD of equal total mass. Yamaguchi and Harnpornchai [7] reported improved performance of optimum MTMDs as compared to optimum single TMD. In addition, they reported that MTMDs can be much more robust than single TMD. Abe and Fujino [8] showed that the MTMDs are efficient when at least one of the oscillators is strongly coupled with the structure in any mode. In addition, they showed that properly designed MTMDs are robust than a conventional single TMD. Kareem and Kline [9] had 


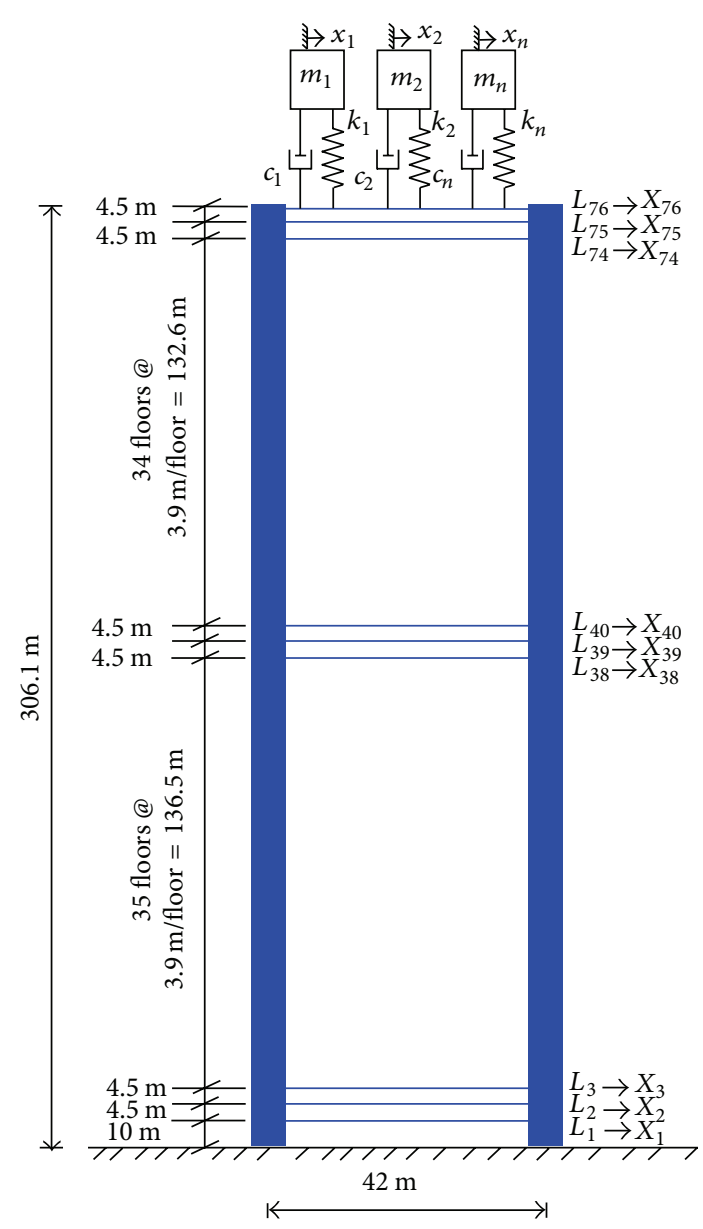

(a)

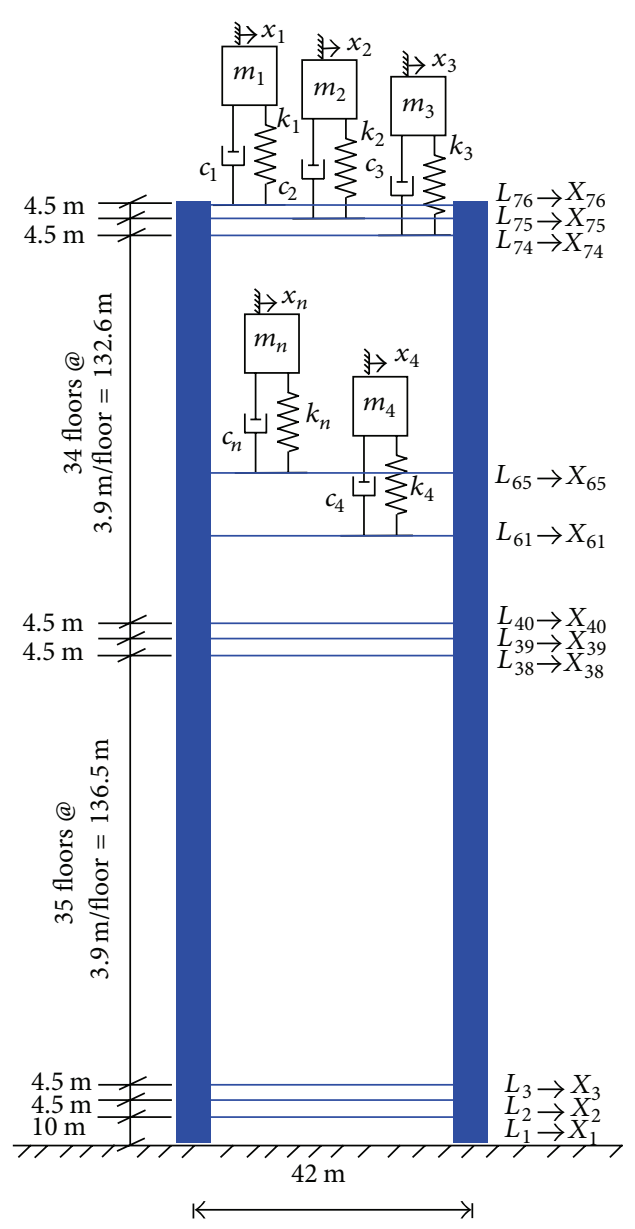

(b)

FIGURE 1: Model of 76-storey benchmark building installed with (a) MTMDs all at top floor, (b) d-MTMDs along height of the building.

investigated the dynamic characteristics and effectiveness of the MTMDs with distributed natural frequencies under random loading. They reported that the MTMDs were most effective in controlling the motion of the primary system. In addition, they reported that the MTMDs require less space for an individual damper than one massive STMD, which improves their constructability and maintenance. Jangid [10] investigated the optimum parameters of the MTMDs for undamped main system. He reported that by increasing the number of TMDs the optimum damping ratio of the MTMDs decreases and the damping increases with increase in the mass ratio. In addition, he reported that optimum bandwidth of the MTMD system increases with the increase of both of the mass and number of MTMDs. Further, it was showed that optimum tuning frequency increases with the increase in the number of MTMDs and decreases with the increase in the mass ratio. $\mathrm{Li}[11,12]$ reported improved performance of optimum MTMDs as compared to the optimum STMD. In addition, the researcher showed that the MTMDs are more robust as compared to the STMD. Chen and Wu [13] studied the effects of a TMD on the modal responses of a sixstorey building to demonstrate the damper's ineffectiveness in seismic applications. They reported that the MTMDs are more effective in suppressing the accelerations at lower floors than at upper floors. In addition, the researchers reported that the MTMDs do not appear advantageous over a conventional STMD for displacement control. Bakre and Jangid [14] studied the optimum parameters of the MTMD system, wherein the damping ratio and tuning frequency bandwidth were obtained using the numerical searching technique for different values of number and mass ratio of the MTMDs. Han and $\mathrm{Li}$ [15] had reported the effectiveness of the MTMDs with their natural frequencies being uniformly distributed around their mean natural frequency. The study recommended using the MTMDs with identical stiffness and damping coefficient, however with unequal mass and uniform distribution of natural frequencies. Lin et al. [16] showed the effectiveness of the optimum MTMDs with limited stroke length. They showed with the help of experimental results that the MTMDs were not only effective in mitigating the building responses but also successful in suppressing its stroke. Moon [17] had concluded that loss of effectiveness of the MTMDs is minimal if they are distributed vertically based on mode shape. A study reported by Patil 
and Jangid [18] showed that optimum MTMDs are much more effective and robust as compared to a single TMD for the wind excited benchmark building. However, hardly has any study so far been conducted on wind response control of buildings wherein placement and tuning of the MTMDs are made in accordance with the modal proprieties of the building. The objective of this study, therefore, is to study effective placement of TMDs based on the mode shapes and frequencies of the main structure. The TMDs are placed where the mode shape amplitude of the building is the largest or large in the particular mode and the TMDs are tuned to higher modal frequencies while controlling first five modes for mitigation of building vibration under across-wind load. On a particular floor not more than one TMD is proposed to be installed. The vibration control strategy adopted here is termed as multimode control.

\section{Mathematical Model of Benchmark Building}

For this study, a 76-storey benchmark building is considered, having $306.1 \mathrm{~m}$ height and $42 \mathrm{~m} \times 42 \mathrm{~m}$ plan dimension. It is sensitive to wind induced loads because the aspect ratio (height to width ratio) is 7.3. The first storey is $10 \mathrm{~m}$ high; stories from 2 and 3, 38-40, and 74-76 are $4.5 \mathrm{~m}$ high; all other stories are having typical height of $3.9 \mathrm{~m}$. Yang et al. [19] have given detailed description of the benchmark building and its mathematical model. In the model, the rotational degrees of freedom have been removed by the static condensation procedure, only translational degrees of freedom; one at each floor of the building is considered [19]. Figure 1(a) shows the elevation of benchmark building installed with MTMDs all at top floor, and Figure 1(b) shows the elevation of benchmark building installed with d-MTMDs on different floors. In addition, the heights of various floors and configuration of the MTMDs have also been depicted.

The governing equations of motion for the wind excited benchmark building installed with all MTMDs at top floor and installed with d-MTMDs are obtained by considering the equilibrium of forces at the location of each degree of freedom as follows:

$$
\left[M_{s}\right]\left\{\ddot{x}_{s}\right\}+\left[C_{s}\right]\left\{\dot{x}_{s}\right\}+\left[K_{s}\right]\left\{x_{s}\right\}=\left\{F_{t}\right\},
$$

where $\left[M_{s}\right],\left[C_{s}\right]$, and $\left[K_{s}\right]$ are the mass, damping, and stiffness matrices of the building, respectively, of order $(N+$ $n) \times(N+n)$. Here, $N$ indicates degrees of freedom (DOF) for the benchmark building and $n$ indicates degrees of freedom for MTMDs/STMD. $\left\{x_{s}\right\}=\left\{X_{1}, X_{2}, \ldots, X_{N}, \ldots, x_{n}\right\}^{T}=$ $\left\{\left\{X_{i}\right\},\left\{x_{j}\right\}\right\}^{T},\left\{\dot{x}_{s}\right\}$, and $\left\{\ddot{x}_{s}\right\}$ are the unknown relative floor displacement, velocity, and acceleration vectors, respectively; and $\left\{F_{t}\right\}$ is the wind load vector of order $(N+n)$.

Wind load is considered acting on the $N$ floors of the building but not on the TMDs. The detailed description of the wind tunnel tests conducted at the University of Sydney is given by Samali et al. $[20,21]$ and the time histories of across-wind loads are available at the website [22]. Power spectral density function (PSDF) of the wind load applied on the building is shown in Figure 2. Locations for installation

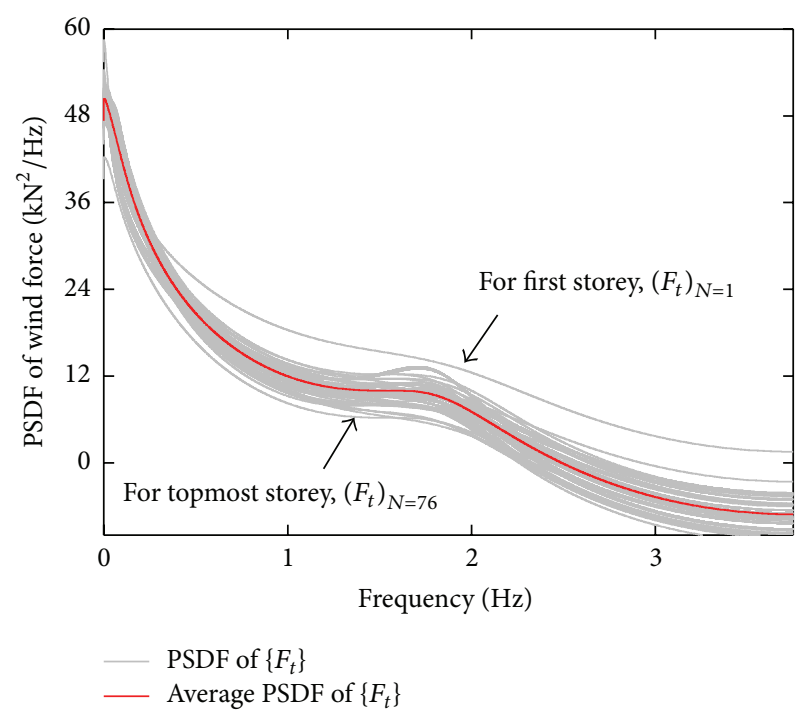

FIgURE 2: The PSDF of the wind forces applied on building.

of the TMDs are identified based on the mode shapes of the uncontrolled building and subsequently based on the controlled building in a step-by-step manner. The TMDs are placed where the mode shape amplitude of the building is the largest in the particular mode and each of the TMDs is tuned with the corresponding modal frequency. Next larger amplitude is preferred over the largest when already a TMD is installed on a particular floor.

Figure 3 shows the first five mode shapes of the uncontrolled/controlled building and the placement of the five TMDs as follows: TMD-1 at 76th floor, that is, at the topmost floor; TMD-2 at 75th floor; TMD-3 at 74th floor; TMD-4 at 61st floor; and TMD-5 at 65th floor. Note that while the placement of the TMDs is in accordance with the largest or large amplitude of the mode shape, not more than one TMD is placed on one floor, which would ease installation intricacies of the TMDs. In addition, placement of subsequent TMD has been made taking in to account the modified mode shape due to the addition of the TMD in the preceding step. The first five natural frequencies of the uncontrolled (NC) building are $0.1600,0.7651,1.9921,3.7899$, and $6.3945 \mathrm{~Hz}$, which were the tuning frequencies for the TMD-1, TMD-2, TMD-3, TMD4, and TMD-5, respectively, controlling the corresponding modes. Efficacy of the d-MTMDs is established by comparing three cases: (i) placing one TMD at the topmost floor denoted by STMD; (ii) placing five TMDs at the topmost floor denoted by MTMDs; and (iii) the abovementioned pattern of five distributed TMDs on different floors denoted by d-MTMDs. Only first five modes are controlled in this work as they predominantly influence the total dynamic response, their modal mass $\left[M_{r}\right]$ participation being $90 \%$ or greater. For the building considered herein, $90 \%$ of mass of the building participated in the first five modes, which have been decided to control.

Figure 4 shows the procedure followed for (a) placement of the d-MTMDs and (b) optimization of parameters of 


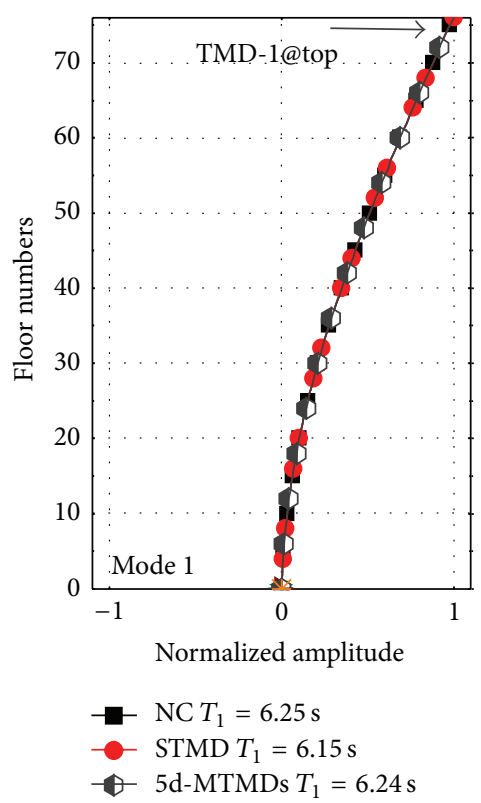

(a)

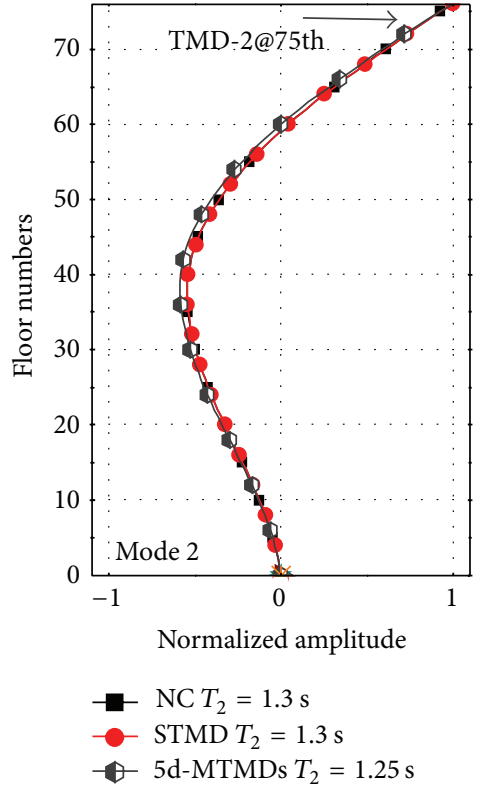

(b)

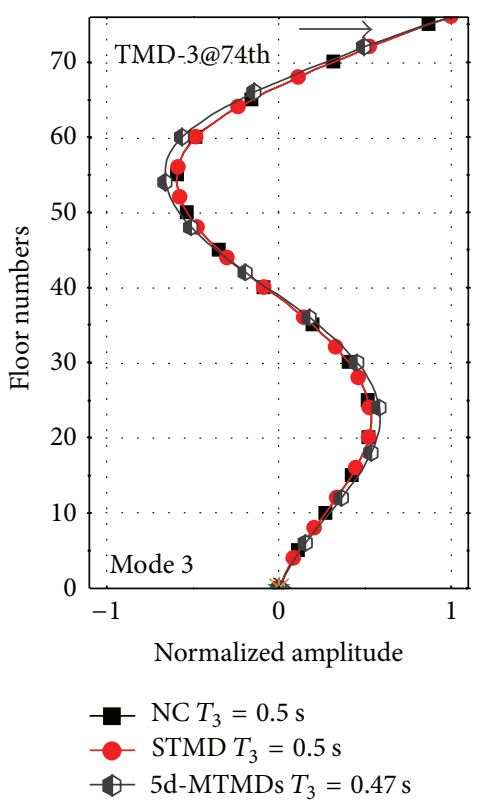

(c)

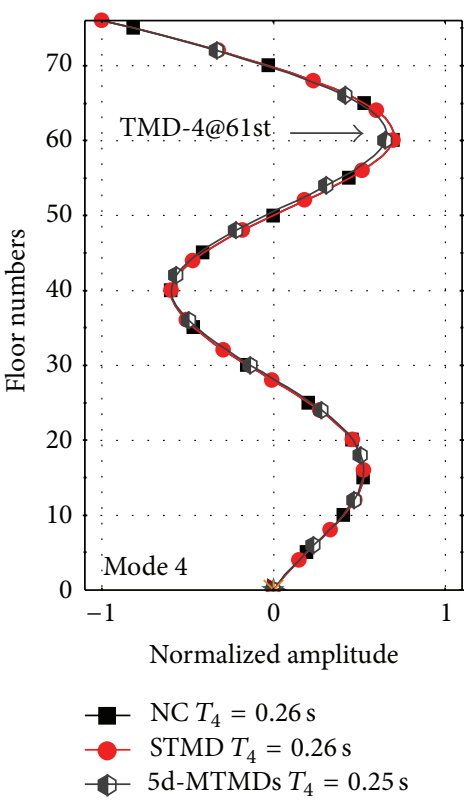

(d)

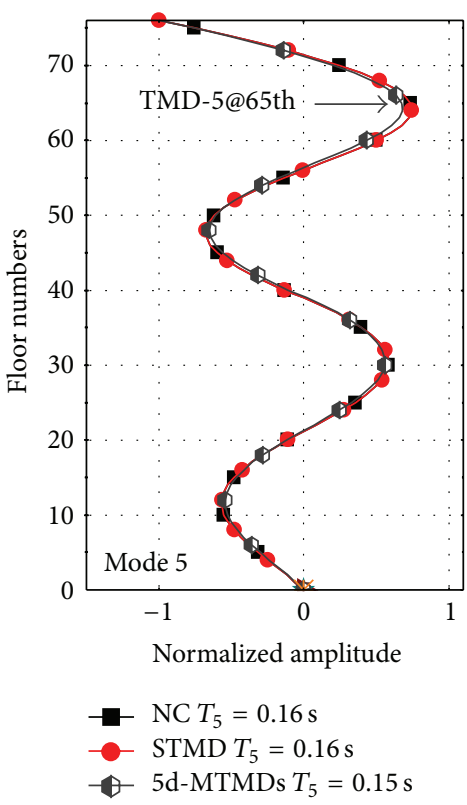

(e)

FIGURE 3: First five mode shapes of uncontrolled and controlled 76-storey benchmark building.

the d-MTMDs. The modal analysis is conducted to find the natural frequencies $\left[\Omega_{i}, \omega_{j}\right]$, mode shapes $\left\{\phi_{i, j}\right\}$, and modal mass contribution $\left[M_{r}\right]$ of the uncontrolled and controlled building using its stiffness $\left[K_{s}\right]$ and mass $\left[M_{s}\right]$ matrices for $(N+n)$ degrees of freedom (DOF). The first TMD is located at the largest amplitude in first mode shape, $\phi_{1}$ : top floor in this building. The number of modes to be controlled is based on at least $90 \%$ of the total mass of the building contributing in the modal response. Subsequently, the parameters of the TMDs are optimized by assuming their stiffness to be the same. The masses of TMDs are calculated from the known frequencies and stiffness of the TMDs. The mass ratio, $\mu=m_{n} / M_{N}$, is assumed to be 0.0082 as recommended by Patil and Jangid [18], and this value is kept the same in all cases of $n$ TMDs for comparison purpose. Thus, the effectiveness of TMD installed on a structure will depend on mass ratio $(\mu)$ between the total mass of the TMDs, $m_{n}=\sum_{j=1}^{j=n} m_{j}$, and the building, $M_{N}=\sum_{i=1}^{i=N} M_{i}$. The total mass of the STMD, MTMDs, and 


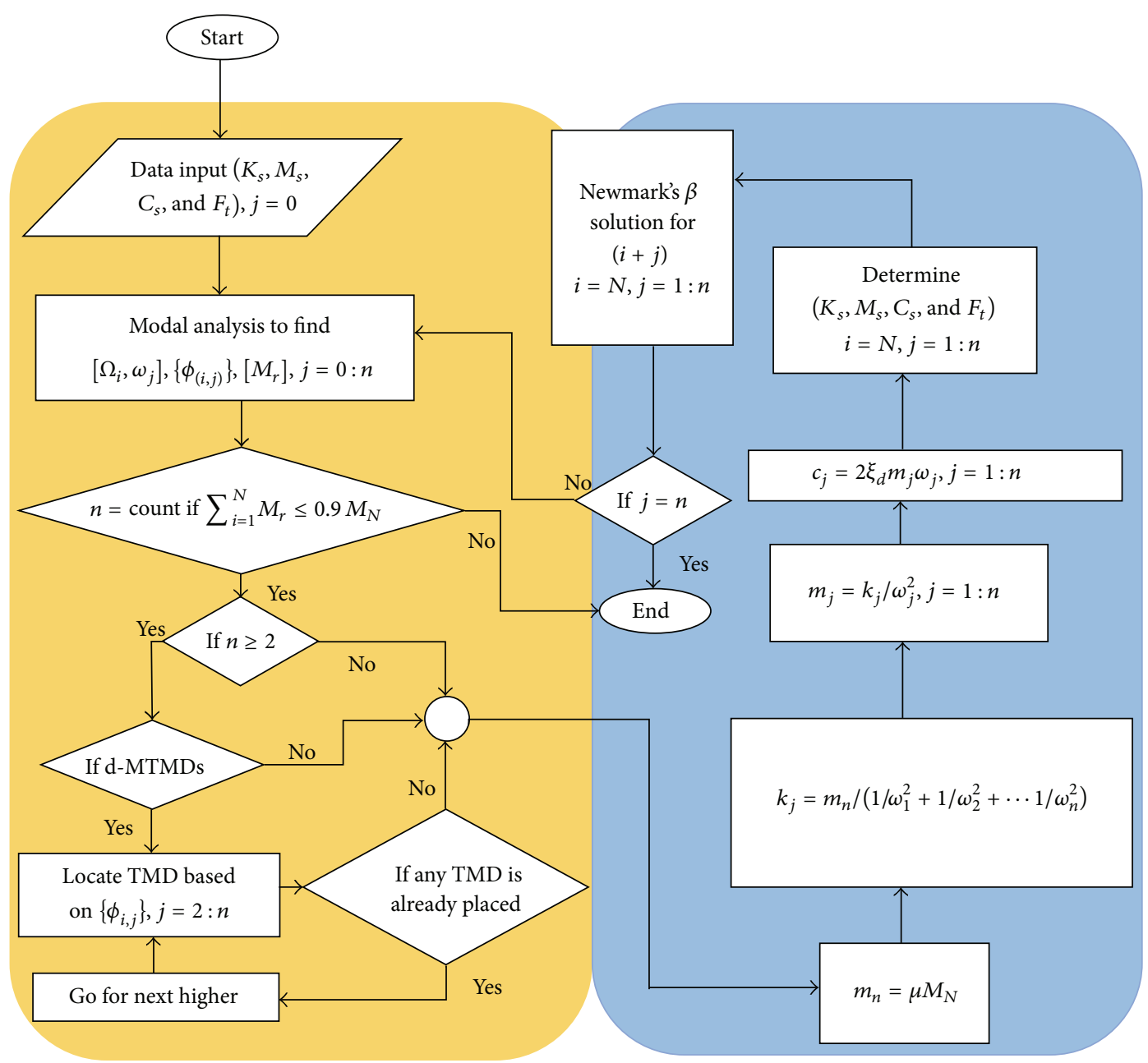

\section{Location optimizer}

Parameter $\left(m_{j}, k_{j}, c_{j}\right)$ optimizer

FIGURE 4: Flowchart for optimizing location and design parameters of d-MTMDs for wind response control of 76-storey benchmark building.

d-MTMDs is kept the same for comparison purpose in all the cases investigated. In the three cases, STMD, MTMDs, and
d-MTMDs, the mass matrix is of order $(N+n) \times(N+n)$ as follows:

$$
\left[M_{s}\right]=\left[\begin{array}{cccccccccc}
M_{1} & 0 & 0 & \cdots & 0 & 0 & 0 & 0 & \cdots & 0 \\
0 & M_{2} & 0 & \cdots & 0 & 0 & 0 & 0 & \cdots & 0 \\
0 & 0 & M_{3} & \cdots & 0 & 0 & 0 & 0 & \cdots & 0 \\
\vdots & \vdots & \vdots & \ddots & \vdots & \vdots & \vdots & \vdots & \ddots & \vdots \\
0 & 0 & 0 & \cdots & M_{N-1} & 0 & 0 & 0 & \cdots & 0 \\
0 & 0 & 0 & \cdots & 0 & M_{N} & 0 & 0 & \cdots & 0 \\
\vdots & \vdots & \vdots & \cdots & \vdots & 0 & m_{1} & 0 & \cdots & 0 \\
0 & 0 & 0 & \cdots & \vdots & 0 & 0 & m_{2} & \cdots & 0 \\
\vdots & \vdots & \vdots & \ddots & \vdots & \vdots & \vdots & \vdots & \ddots & \vdots \\
0 & 0 & 0 & \cdots & 0 & 0 & 0 & 0 & \cdots & m_{n}
\end{array}\right] .
$$


For the building installed with the STMD, MTMDs, or dMTMDs, stiffness and damping of the TMDs were input in the generic stiffness matrix $\left[K_{s}\right]$ and damping matrix $\left[C_{s}\right]$ as follows:

$$
\left[K_{s}\right]=\left[\begin{array}{cccccccccc}
K_{1}+K_{2}+k_{n} & -K_{2} & 0 & \cdots & 0 & 0 & 0 & 0 & \cdots & -k_{n} \\
-K_{2} & K_{2}+K_{3} & -K_{3} & \cdots & 0 & 0 & 0 & 0 & \cdots & 0 \\
0 & -K_{3} & K_{3}+K_{4} & \cdots & 0 & 0 & 0 & 0 & \cdots & 0 \\
\vdots & \vdots & \vdots & \ddots & \vdots & \vdots & \vdots & \vdots & \ddots & \vdots \\
0 & 0 & 0 & \cdots & K_{N-1}+K_{N}+k_{2} & -K_{N} & 0 & -k_{2} & \cdots & 0 \\
0 & 0 & 0 & \cdots & -K_{N} & K_{N}+k_{1} & -k_{1} & 0 & \cdots & 0 \\
\vdots & \vdots & \vdots & \cdots & \vdots & -k_{1} & k_{1} & 0 & \cdots & 0 \\
0 & 0 & 0 & \cdots & -k_{2} & 0 & 0 & k_{2} & \cdots & 0 \\
\vdots & \vdots & \vdots & \ddots & \vdots & \vdots & \vdots & \vdots & \ddots & \vdots \\
-k_{n} & 0 & 0 & \cdots & 0 & 0 & 0 & 0 & \cdots & k_{n}
\end{array}\right] \text {, }
$$

$$
\left[C_{s}\right]=\left[\begin{array}{cccccccccc}
C_{1}+C_{2}+c_{n} & -C_{2} & 0 & \cdots & 0 & 0 & 0 & 0 & \cdots & -c_{n} \\
-C_{2} & C_{2}+C_{3} & -C_{3} & \cdots & 0 & 0 & 0 & 0 & \cdots & 0 \\
0 & -C_{3} & C_{3}+C_{4} & \cdots & 0 & 0 & 0 & 0 & \cdots & 0 \\
\vdots & \vdots & \vdots & \ddots & \vdots & \vdots & \vdots & \vdots & \ddots & \vdots \\
0 & 0 & 0 & \cdots & C_{N-1}+C_{N}+c_{2} & -C_{N} & 0 & -c_{2} & \cdots & 0 \\
0 & 0 & 0 & \cdots & -C_{N} & C_{N}+c_{1} & -c_{1} & 0 & \cdots & 0 \\
\vdots & \vdots & \vdots & \cdots & \vdots & -c_{1} & c_{1} & 0 & \cdots & 0 \\
0 & 0 & 0 & \cdots & -c_{2} & 0 & 0 & c_{2} & \cdots & 0 \\
\vdots & \vdots & \vdots & \ddots & \vdots & \vdots & \vdots & \vdots & \ddots & \vdots \\
-c_{n} & 0 & 0 & \cdots & 0 & 0 & 0 & 0 & \cdots & c_{n}
\end{array}\right] .
$$

The above mentioned $\left[M_{s}\right],\left[C_{s}\right]$, and $\left[K_{s}\right]$ matrices of the building are obtained when rotational degrees of freedom at each floor level are ignored as presented earlier by Elias and Matsagar [23]. However, in the tall building considered here it is recommendable to consider the rotational degrees of freedom at each floor level. Nevertheless, the rotational degrees of freedom can be condensed and only translational degrees of freedom can be retained in the wind response analysis. The condensed stiffness matrix in NC case $\left[K_{N}\right]$ is calculated by removing the rotation degrees of freedom by static condensation, whereas the damping matrix, $\left[C_{N}\right]$ is not explicitly known but can be defined using Rayleigh's approach with damping ratio $\left(\zeta_{s}=0.01\right)$ for five modes. For the building installed with the STMD, MTMDs, or d-MTMDs, the stiffness and damping of the TMDs are incorporated in the generic stiffness matrix $\left[K_{s}\right]$ and damping matrix $\left[C_{s}\right]$ defined, respectively, in (3) and (4) with corresponding displacement and velocity vectors, as follows:

$$
\begin{aligned}
{\left[K_{s}\right]\left\{x_{s}\right\}=} & {\left[\begin{array}{cc}
{\left[K_{N}\right]_{N \times N}} & {[0]_{N \times n}} \\
{[0]_{n \times N}} & {[0]_{n \times n}}
\end{array}\right]\left\{\begin{array}{c}
\left\{X_{i}\right\}_{N \times 1} \\
\{0\}_{n \times 1}
\end{array}\right\} } \\
& +\left[\begin{array}{cc}
{\left[K_{n}\right]_{N \times N}} & -\left[K_{n}\right]_{N \times n} \\
-\left[K_{n}\right]_{n \times N} & {\left[K_{n}\right]_{n \times n}}
\end{array}\right]\left\{\begin{array}{c}
\left\{X_{i}\right\}_{N \times 1} \\
\left\{x_{j}\right\}_{n \times 1}
\end{array}\right\},
\end{aligned}
$$

$$
\begin{aligned}
{\left[C_{s}\right]\left\{\dot{x}_{s}\right\}=} & {\left[\begin{array}{cc}
{\left[C_{N}\right]_{N \times N}} & {[0]_{N \times n}} \\
{[0]_{n \times N}} & {[0]_{n \times n}}
\end{array}\right]\left\{\begin{array}{c}
\left.\dot{X}_{i}\right\}_{N \times 1} \\
\{0\}_{n \times 1}
\end{array}\right\} } \\
& +\left[\begin{array}{cc}
{\left[C_{n}\right]_{N \times N}} & -\left[C_{n}\right]_{N \times n} \\
-\left[C_{n}\right]_{n \times N} & {\left[C_{n}\right]_{n \times n}}
\end{array}\right]\left\{\begin{array}{c}
\left\{\dot{X}_{i}\right\}_{N \times 1} \\
\left\{\dot{x}_{j}\right\}_{n \times 1}
\end{array}\right\},
\end{aligned}
$$

in which $\left[K_{n}\right]$ and $\left[C_{n}\right]$ are the stiffness and damping matrices corresponding to the degrees of freedom of the TMDs.

The first five modal frequencies to be controlled and frequency of each TMD are calculated as

$$
\begin{gathered}
f_{1}=\frac{\omega_{1}}{\Omega_{1}}, \quad f_{2}=\frac{\omega_{2}}{\Omega_{2}}, \quad f_{3}=\frac{\omega_{3}}{\Omega_{3}}, \\
f_{4}=\frac{\omega_{4}}{\Omega_{4}}, \quad f_{5}=\frac{\omega_{5}}{\Omega_{5}},
\end{gathered}
$$

where the tuning frequency ratios are $f_{1}=f_{2}=\cdots=f_{5}=$ 1. Moreover, $\omega_{1}$ to $\omega_{5}$ and $\Omega_{1}$ to $\Omega_{5}$ are the frequencies of the TMD and first five natural frequencies of the building, respectively. In the MTMD devices, it is more suitable to design a set of TMD units with equal stiffness, $k_{1}=k_{2}=k_{3}=$ $\cdots=k_{n}$, rather than identical masses. Therefore, stiffness $\left(k_{j}\right)$ of the TMDs is calculated as

$$
k_{j}=\frac{m_{n}}{\left(1 / \omega_{1}^{2}+1 / \omega_{2}^{2}+\cdots\left(1 / \omega_{n}^{2}\right)\right)} \quad \text { for } j=1 \text { to } 5 \text {. }
$$




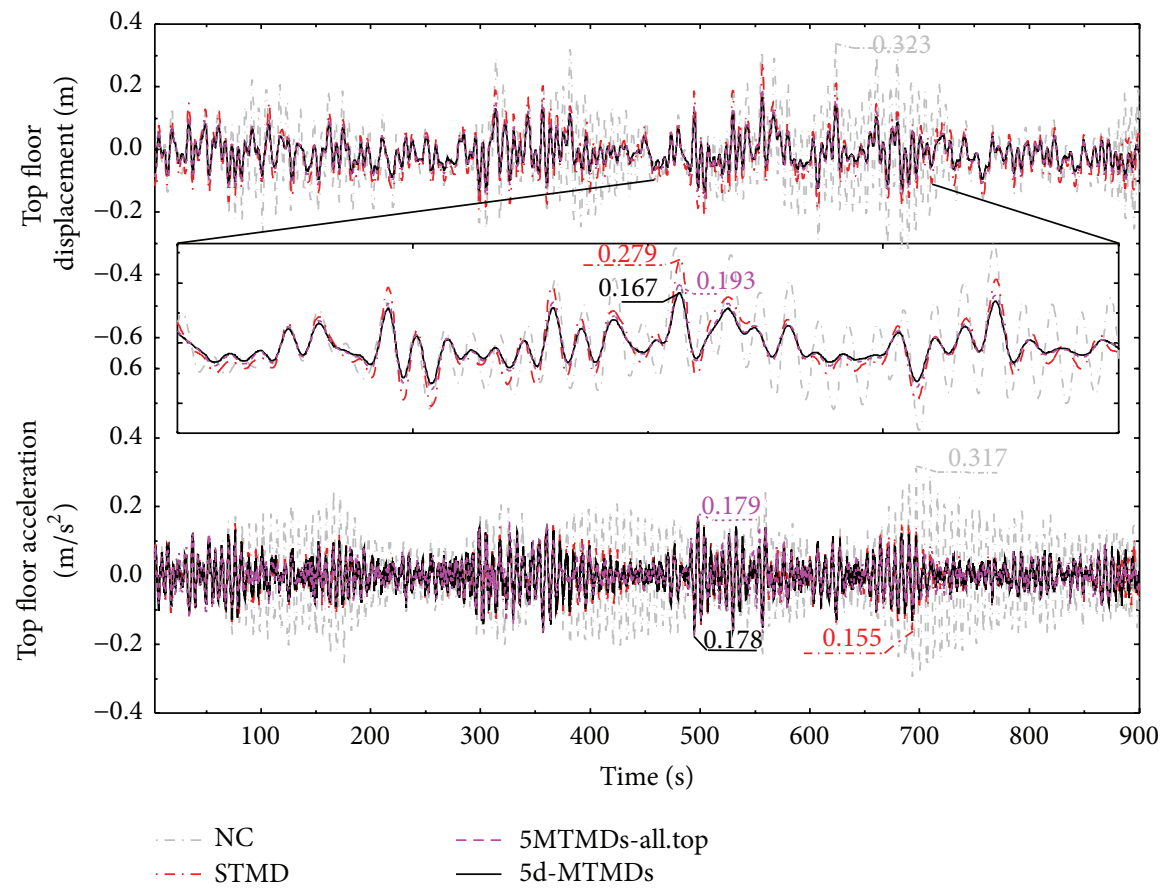

FIGURE 5: Time variation of top floor displacement and top floor acceleration for 76-storey benchmark building under wind forces.

Here, $m_{n}$ is calculated for a particular mass ratio, $\mu$. The mass $\left(m_{j}\right)$ is used for adjusting the frequency of each TMD unit such that

$$
m_{j}=\frac{k_{j}}{\omega_{j}^{2}} \text { for } j=1 \text { to } 5 \text {. }
$$

The damping ratios $\left(\xi_{d}=\xi_{1}=\xi_{2}=\cdots \xi_{n}\right)$ of the TMDs are kept the same and the damping $\left(c_{j}\right)$ of the TMDs is calculated as

$$
c_{j}=2 \xi_{d} m_{j} \omega_{j} \text { for } j=1 \text { to } 5 .
$$

\section{Solution of Equations of Motion}

Classical modal superposition technique cannot be employed in the solution of equations of motion here because the system is nonclassically damped owing to the difference in the damping in system with TMDs as compared to the damping in the system with no control. Therefore, the equations of motion are solved numerically using Newmark's method of step-by-step integration, adopting linear variation of acceleration over a small time interval of $\Delta t$. The time interval for solving the equations of motion is taken as $0.1333 / 100 \mathrm{~s}$.

\section{Numerical Study}

A comparison of wind responses is made for the linear model of the 76-storey benchmark building installed with the STMD, MTMDs all on top floor, and d-MTMDs. In Figure 5, time variation of top floor displacement and top floor acceleration for the 76-storey benchmark building under wind forces are plotted for the cases of (i) uncontrolled (NC), (ii) controlled by single-TMD (STMD), (iii) controlled by installing five MTMDs on top floor of the benchmark building (5MTMDs-all.top), and (iv) controlled by five distributed MTMDs (5d-MTMDs). The mass ratio for the STMD is assumed to be 0.0082 of the total mass of the building, and total mass of the MTMD is taken equal to mass of the STMD. The peak top floor displacements for these four cases are $0.323 \mathrm{~m}, 0.279 \mathrm{~m}, 0.193 \mathrm{~m}$, and $0.167 \mathrm{~m}$, respectively; and the peak top floor accelerations are $0.317 \mathrm{~m} / \mathrm{s}^{2}, 0.155 \mathrm{~m} / \mathrm{s}^{2}$, $0.179 \mathrm{~m} / \mathrm{s}^{2}$, and $0.178 \mathrm{~m} / \mathrm{s}^{2}$, respectively. It is observed that the maximum reduction of top floor displacement is achieved when the d-MTMDs are installed as per the optimized location and design parameters (Figure 4). As compared to the uncontrolled structure (NC), the top floor displacements are reduced by around $15 \%, 40 \%$, and $50 \%$, respectively, when STMD, all MTMDs at top floor, and d-MTMDs are installed. The top floor acceleration is also reduced in all controlled cases significantly as compared to the NC case; nevertheless, maximum reduction in the acceleration is achieved in case of the STMD installation. As compared to the uncontrolled structure (NC), the top floor accelerations are reduced by around $50 \%, 45 \%$, and $45 \%$, respectively, when STMD, all MTMDs at top floor, and d-MTMDs are installed.

Optimum number of dampers, $n$, should be determined for improving control performance, economy, and constructional feasibility. To facilitate direct comparisons and to show the performance of various devices a set of twelve performance criteria are proposed by Yang et al. [19] for the 76 -storey benchmark building. To measure the reduction in root mean square (RMS) response quantities of the wind excited benchmark building, the performance criteria $J_{1}$ to $J_{4}$ 

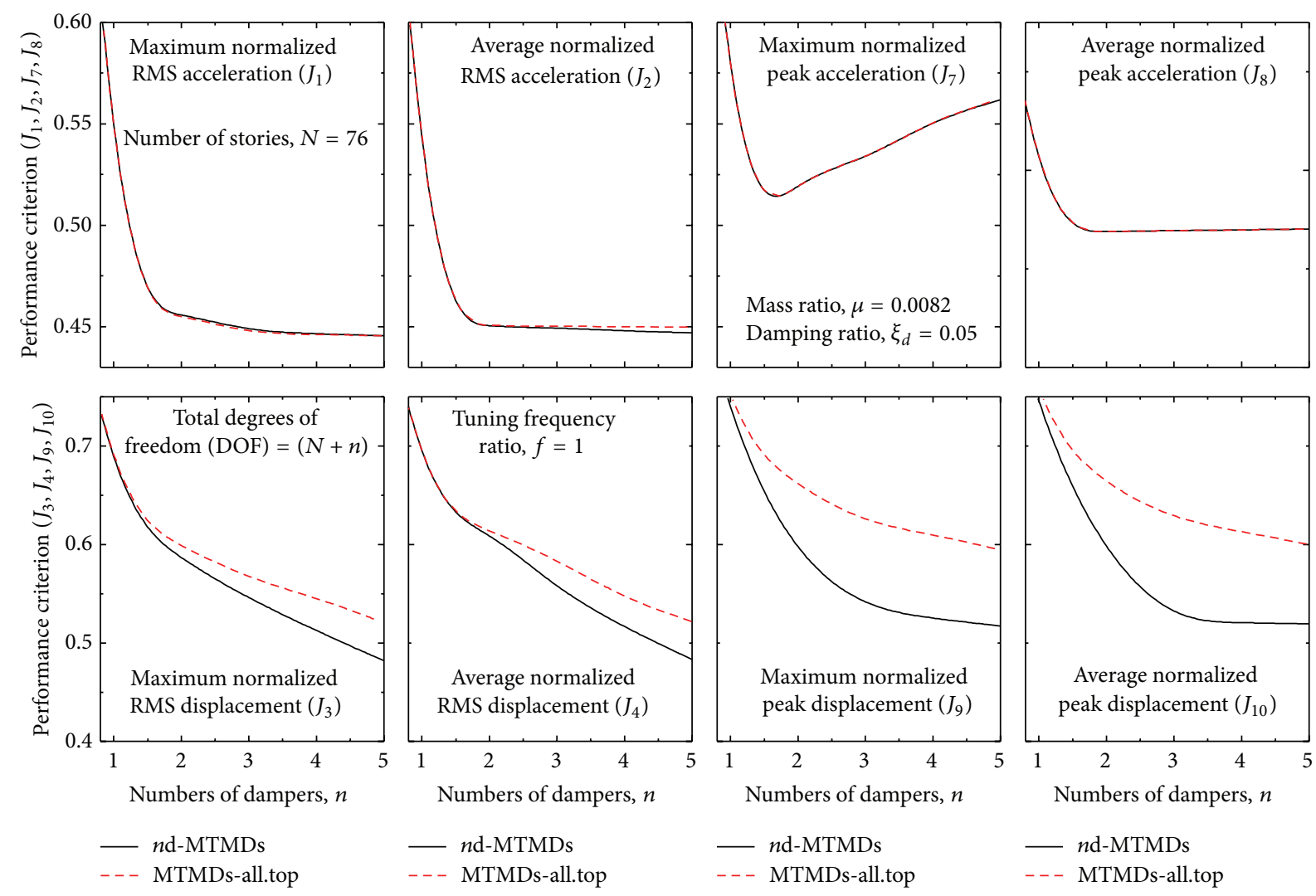

FIgURE 6: Variation of performance criteria $J_{1}$ to $J_{4}$ and $J_{7}$ to $J_{10}$ with number of d-MTMDs and MTMDs.

are defined. These response quantities with control measures are normalized by the response quantities of the uncontrolled building.

The first evaluation criterion for the controllers is their ability to reduce the maximum floor RMS acceleration. A nondimensional form of this performance criterion is given by

$$
J_{1}=\max \frac{\left(\sigma_{\ddot{X} 1}, \sigma_{\ddot{X} 30}, \sigma_{\ddot{X} 50}, \sigma_{\ddot{X} 55}, \sigma_{\ddot{X} 60}, \sigma_{\ddot{X} 65}, \sigma_{\ddot{X} 70}, \sigma_{\ddot{X} 75}\right)}{\sigma_{\ddot{X} 75 o}},
$$

where $\sigma_{\ddot{X} i}=$ RMS acceleration of the $i$ th floor and $\sigma_{\ddot{X} 75 o}=$ $0.091 \mathrm{~m} / \mathrm{s}^{2}=$ RMS acceleration of the 75th floor without control.

The second criterion is the average performance of acceleration for selected floors above the 49th floor:

$$
J_{2}=\frac{1}{6} \sum_{i} \frac{\sigma_{\ddot{X} i}}{\sigma_{\ddot{X} i o}}, \quad \text { for } i=50,55,60,65,70,75
$$

where $\sigma_{\ddot{X} i o}=$ RMS acceleration of the $i$ th floor without control.
The third and fourth evaluation criteria are the ability of the controller to reduce the top floor displacements. The normalized forms of the criteria are given as follows:

$$
\begin{gathered}
J_{3}=\frac{\left(\sigma_{X 76}\right)}{\left(\sigma_{X 760}\right)}, \\
J_{4}=\frac{1}{7} \sum_{i} \frac{\left(\sigma_{X i}\right)}{\left(\sigma_{X i o}\right)}, \quad \text { for } i=50,55,60,65,70,75,76,
\end{gathered}
$$

where $\sigma_{X i}$ and $\sigma_{X i 0}=$ RMS displacements of the $i$ th floor with and without control, respectively; $\sigma_{X 760}=0.101 \mathrm{~m}$ is the RMS displacement of the 76th floor of the uncontrolled building.

To find the peak response of controlled structure normalized by the peak response of the uncontrolled building, the performance criteria $J_{7}$ to $J_{10}$ are defined. Because the present study is related to passive system of control, there is no need to consider the other four performance criteria $J_{5}, J_{6}, J_{11}$, and $J_{12}$ which represent the performance of the actuator in active control systems. 


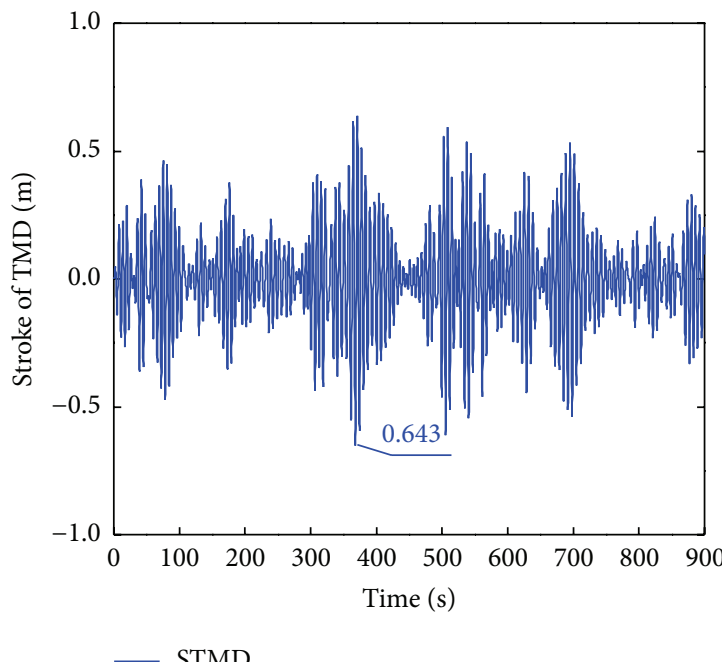

(a)

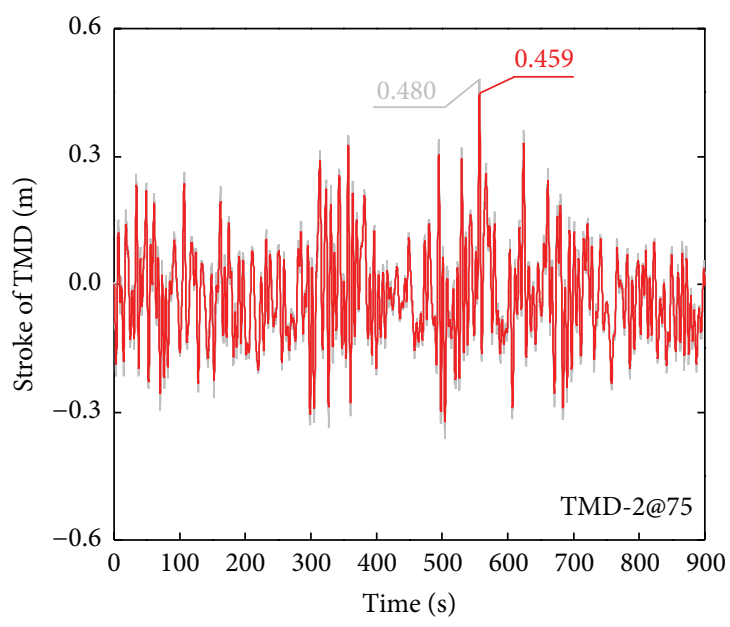

(c)

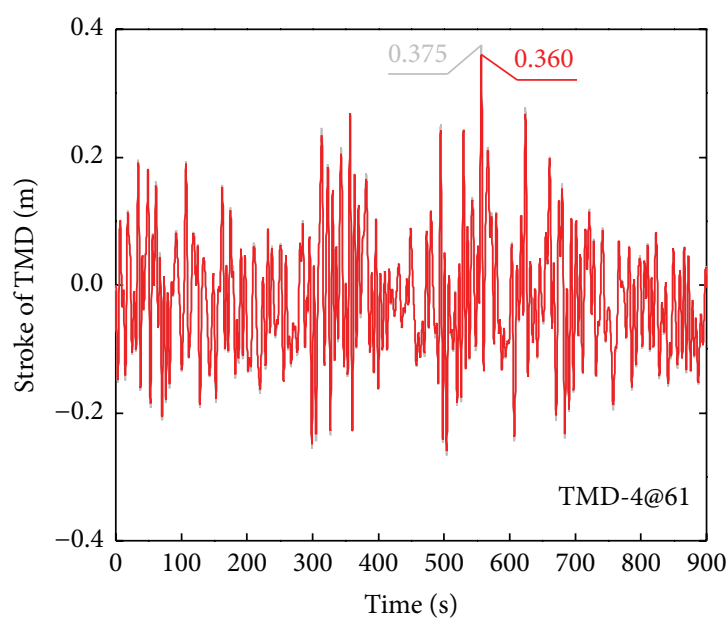

(e)

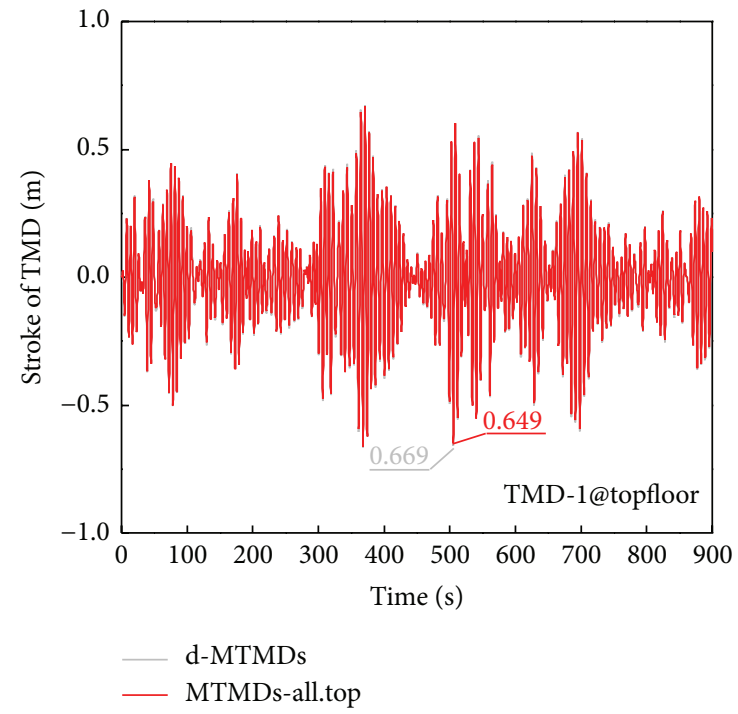

(b)

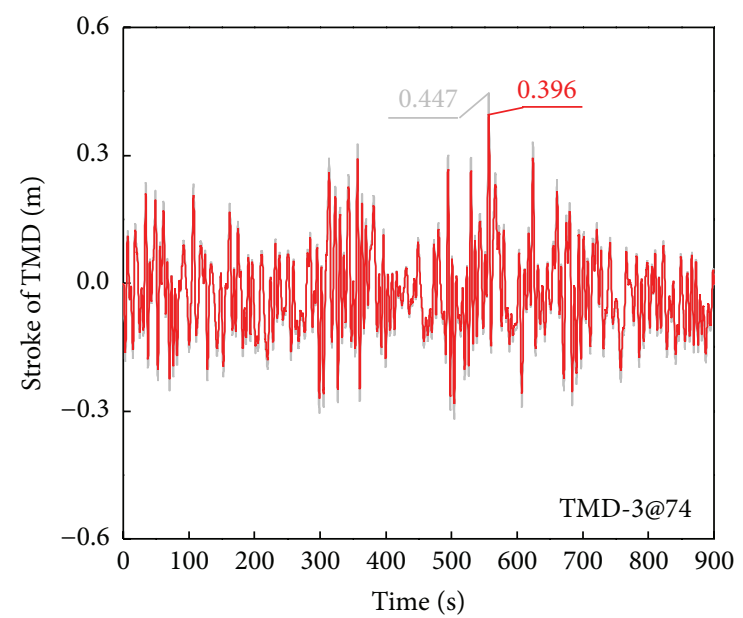

(d)

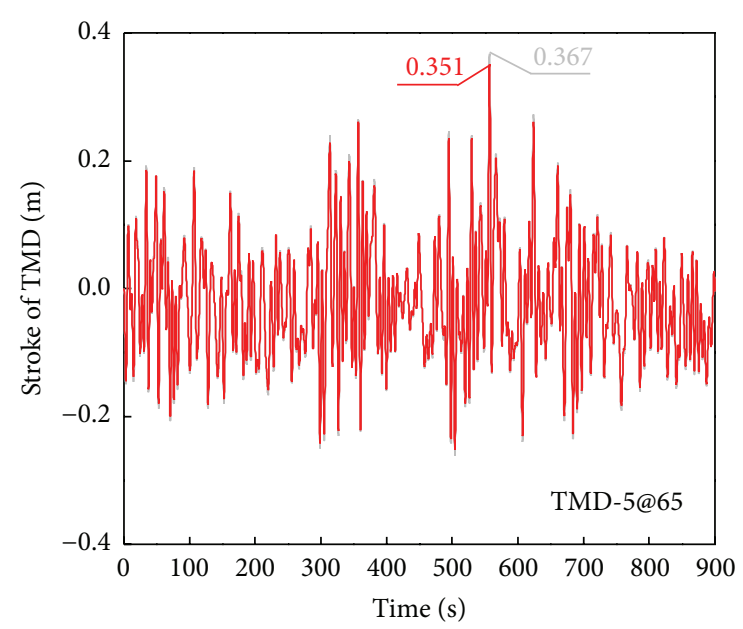

(f)

FIGURE 7: Time variation of the strokes of the STMD, MTMDs, and d-MTMDs. 
The performance in terms of the peak response quantities is also important in design of the system. This set of nondimensional performance criteria is defined as follows:

$$
\begin{gathered}
J_{7}=\frac{\max \left(\ddot{X}_{p 1}, \ddot{X}_{p 30}, \ddot{X}_{p 50}, \ddot{X}_{p 55}, \ddot{X}_{p 60}, \ddot{X}_{p 65}, \ddot{X}_{p 70}, \ddot{X}_{\ddot{x} 75}\right)}{\left(\ddot{X}_{p 750}\right)}, \\
J_{8}=\frac{1}{6} \sum_{i} \frac{\left(\ddot{X}_{p i}\right)}{\left(\ddot{X}_{p i o}\right)}, \quad \text { for } i=50,55,60,65,70,75, \\
J_{9}=\frac{\left(X_{p 76}\right)}{\left(X_{p 760}\right)}, \\
J_{10}=\frac{1}{7} \sum_{i} \frac{\left(X_{p i}\right)}{\left(X_{p i o}\right)}, \quad \text { for } i=50,55,60,65,70,75,76,
\end{gathered}
$$

where $X_{p i}$ and $X_{p i o}=$ peak displacements of the $i$ th floor with and without control; $\ddot{X}_{p i}$ and $\ddot{X}_{p i o}=$ peak accelerations of the $i$ th floor with and without control; for instance, $X_{p 76 o}=$ $0.323 \mathrm{~m}$ and $\ddot{X}_{p 75 o}=0.317 \mathrm{~m} / \mathrm{s}^{2}$.

The variations of the performance criteria with increased number of TMDs for a chosen mass ratio are shown in Figure 6. It can be observed that the performance criteria for normalized peak acceleration, $J_{1}, J_{2}, J_{7}$, and $J_{8}$ in both cases, MTMDs and d-MTMDs, have improved significantly. Improved performance is achieved by installing the $\mathrm{d}$ MTMDs as compared to the STMD and MTMDs installations; however, the variations of the performance criteria by increasing the number of TMDs in two cases of MTMDs and d-MTMDs for acceleration are observed to be similar. Most significant advantage of installing the d-MTMDs in improving performance is to control the RMS and peak displacement of the building as compared to when MTMDs and STMD are installed (Figure 6).

To study the performance of the d-MTMDs the number of TMDs is increased up to five, with each controlling different modal response. The improvement in the performance criteria $J_{3}, J_{4}, J_{9}$, and $J_{10}$ is achieved when five modes are controlled in the d-MTMDs with their optimized locations and parameters (Figure 4), as compared to that of the MTMDs all installed at the top floor.

From (7) and (8), it may be inferred that TMD-1 will be more effective as compared to TMD-2, TMD-3, TMD-4, and TMD-5 in the systems, MTMDs-all.top and d-MTMDs. The effectiveness of each TMD can be studied by calculating stroke, such that a TMD unit with higher stroke is more effective. Therefore, strokes of the TMDs in the three systems, STMD, 5MTMDs-all.top, and 5d-MTMDs, are calculated and shown in Figure 7. It is observed that STMD and TMD-1 in both the systems exhibit largest strokes. Thereby, substantial amount of energy of the wind load will be dissipated in the first mode control. In addition, it is also evident from the figure that the performance of the MTMDs-all.top and d-MTMDs is improved as compared to the STMD case. Moreover, the strokes in case of MTMDs-all.top are lower marginally than those in case of the d-MTMDs, thereby signifying effectiveness of the latter. It can therefore be concluded that the TMDs installed to control higher modes are effective.

\section{Conclusions}

Wind response control of a 76-storey benchmark building installed with nondistributed and distributed MTMDs as per modal frequencies and mode shapes is investigated. A comparison of the response of the buildings installed with the TMDs all at top floor and distributed along the height of the building (d-MTMDs) with optimized location and parameters is made. From the trends of the results of the present study, the following conclusions are drawn.

(1) The installation of d-MTMDs is effective in significantly reducing the peak top floor displacement of the building under the wind excitation. The acceleration response is also controlled effectively by the dMTMDs as compared to the STMD and MTMDs.

(2) The installation of d-MTMDs in accordance with the modal properties, that is, modal frequencies and mode shapes, is more effective than the STMD and all TMDs installed on top floor.

(3) The peak displacement response reductions in case of the STMD, MTMDs all at top floor, and d-MTMDs, respectively, are 15\%, 40\%, and 50\%. The peak acceleration response reductions in case of the STMD, MTMDs all at top floor, and d-MTMDs, respectively, are $50 \%, 45 \%$, and $45 \%$.

\section{Conflict of Interests}

The authors declare that there is no conflict of interests regarding the publication of this paper.

\section{References}

[1] H. Frahm, "Device for damping vibration of bodies," US Patent 989958, 1909.

[2] S. E. Randall, D. M. Halsted III, and D. L. Taylor, "Optimum vibration absorbers for linear damped systems," Journal of Mechanical Design, vol. 103, no. 4, pp. 908-913, 1981.

[3] H.-C. Tsai and G.-C. Lin, "Explicit formula for optimum absorber parameters for force excited and viscously damped systems," Journal of Sound and Vibration, vol. 176, no. 5, pp. 585596, 1994.

[4] T. T. Soong and G. F. Dargush, Passive Energy Dissipation Systems in Structural Engineering, John Wily and Sons, Chichester, UK, 1st edition, 1997.

[5] K. Iwanami and K. Seto, "Optimum design of dual tuned mass dampers and their effectiveness," Japan Society of Mechanical Engineering, vol. 50, no. 1, pp. 44-52, 1984.

[6] K. Xu and T. Igusa, "Dynamic characteristics of multiple substructures with closely spaced frequencies," Earthquake Engineering and Structural Dynamics, vol. 21, no. 12, pp. 10591070, 1992. 
[7] H. Yamaguchi and N. Harnpornchai, "Fundamental characteristics of multiple tuned mass dampers for suppressing harmonically forced oscillations," Earthquake Engineering \& Structural Dynamics, vol. 22, no. 1, pp. 51-62, 1993.

[8] M. Abe and Y. Fujino, "Dynamic characterization of multiple tuned mass dampers and some design formulas," Earthquake Engineering \& Structural Dynamics, vol. 23, no. 8, pp. 813-836, 1994.

[9] A. Kareem and S. Kline, "Performance of multiple mass dampers under random loading," Journal of Structural Engineering, vol. 121, no. 2, pp. 348-361, 1995.

[10] R. S. Jangid, "Optimum multiple tuned mass dampers for base-excited undamped system," Earthquake Engineering and Structural Dynamics, vol. 28, no. 9, pp. 1041-1049, 1999.

[11] C. Li, "Performance of multiple tuned mass dampers for attenuating undesirable oscillations of structures under the ground acceleration," Earthquake Engineering and Structural Dynamics, vol. 29, no. 9, pp. 1405-1421, 2000.

[12] C. Li, "Optimum multiple tuned mass dampers for structures under the ground acceleration based on DDMF and ADMF," Earthquake Engineering and Structural Dynamics, vol. 31, no. 4, pp. 897-919, 2002.

[13] G. Chen and J. Wu, "Optimal placement of multiple tuned mass dampers for seismic structures," Journal of Structural Engineering, vol. 127, no. 9, pp. 1054-1062, 2001.

[14] S. V. Bakre and R. S. Jangid, "Optimum multiple tuned mass dampers for base-excited damped main system," International Journal of Structural Stability and Dynamics, vol. 4, no. 4, pp. 527-542, 2004.

[15] B. Han and C. Li, "Characteristics of linearly distributed parameter-based multiple-tuned mass dampers," Structural Control and Health Monitoring, vol. 15, no. 6, pp. 839-856, 2008.

[16] C.-C. Lin, J.-F. Wang, C.-H. Lien, H.-W. Chiang, and C.-S. Lin, "Optimum design and experimental study of multiple tuned mass dampers with limited stroke," Earthquake Engineering \& Structural Dynamics, vol. 39, no. 14, pp. 1631-1651, 2010.

[17] K. S. Moon, "Vertically distributed multiple tuned mass dampers in tall buildings: performance analysis and preliminary design," The Structural Design of Tall and Special Buildings, vol. 19, no. 3, pp. 347-366, 2010.

[18] V. B. Patil and R. S. Jangid, "Optimum multiple tuned mass dampers for the wind excited benchmark building," Journal of Civil Engineering and Management, vol. 17, no. 4, pp. 540-557, 2011.

[19] J. N. Yang, A. K. Agrawal, B. Samali, and J.-C. Wu, "Benchmark problem for response control of wind-excited tall buildings," Journal of Engineering Mechanics, vol. 130, no. 4, pp. 437-446, 2004.

[20] B. Samali, K. C. S. Kwok, G. S. Wood, and J. N. Yang, "Wind tunnel tests for wind-excited benchmark building," Journal of Engineering Mechanics, vol. 130, no. 4, pp. 447-450, 2004.

[21] B. Samali, E. Mayol, K. C. S. Kwok, A. Mack, and P. Hitchcock, "Vibration control of the wind-excited 76-story benchmark building by liquid column vibration absorbers," Journal of Engineering Mechanics, vol. 130, no. 4, pp. 478-485, 2004.

[22] Smart Structures Technology Laboratory, Structural Control: Benchmark Comparisons, SSTL, 2002, http://sstl.cee.illinois .edu/benchmarks/index.html.

[23] S. Elias and V. Matsagar, "Wind response control of 76-storey benchmark building with distributed multiple tuned mass dampers," Journal of Wind and Engineering, vol. 11, no. 2, pp. 37-49, 2014. 

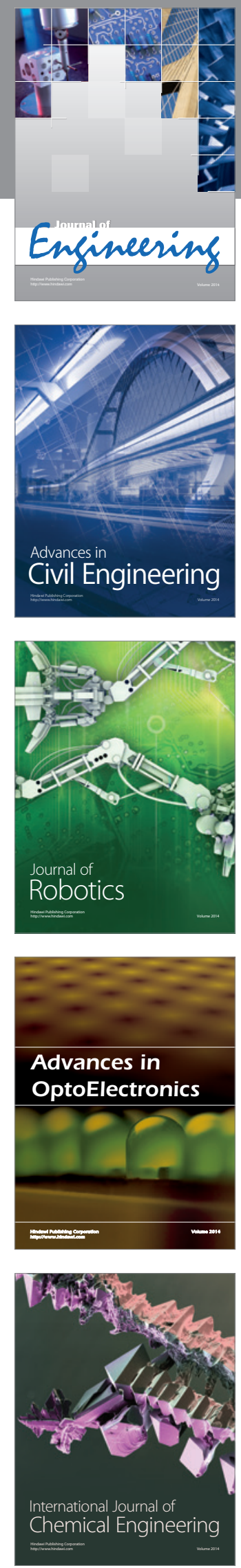

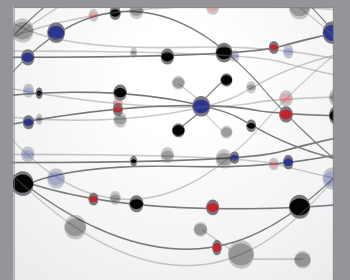

The Scientific World Journal
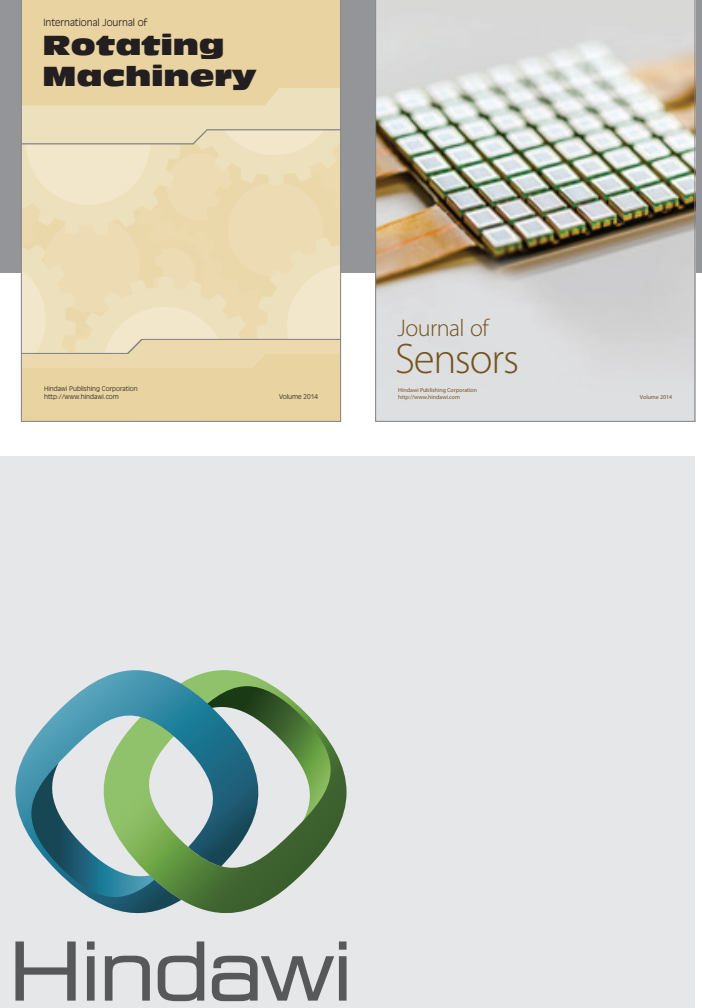

Submit your manuscripts at http://www.hindawi.com
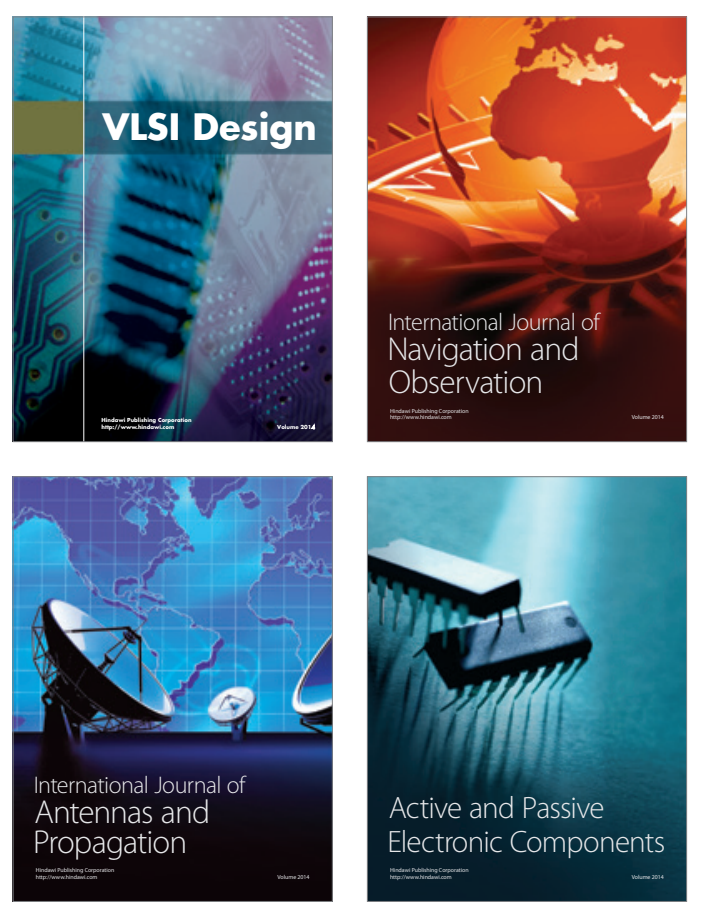
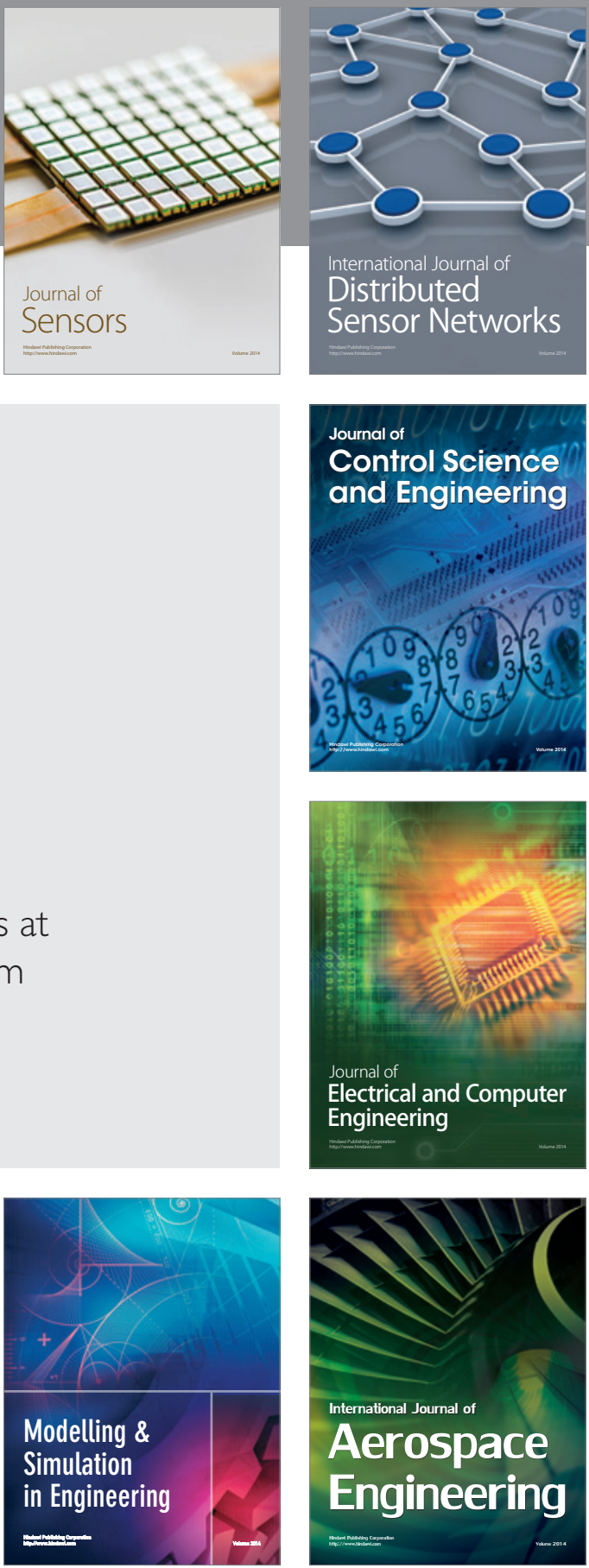

Journal of

Control Science

and Engineering
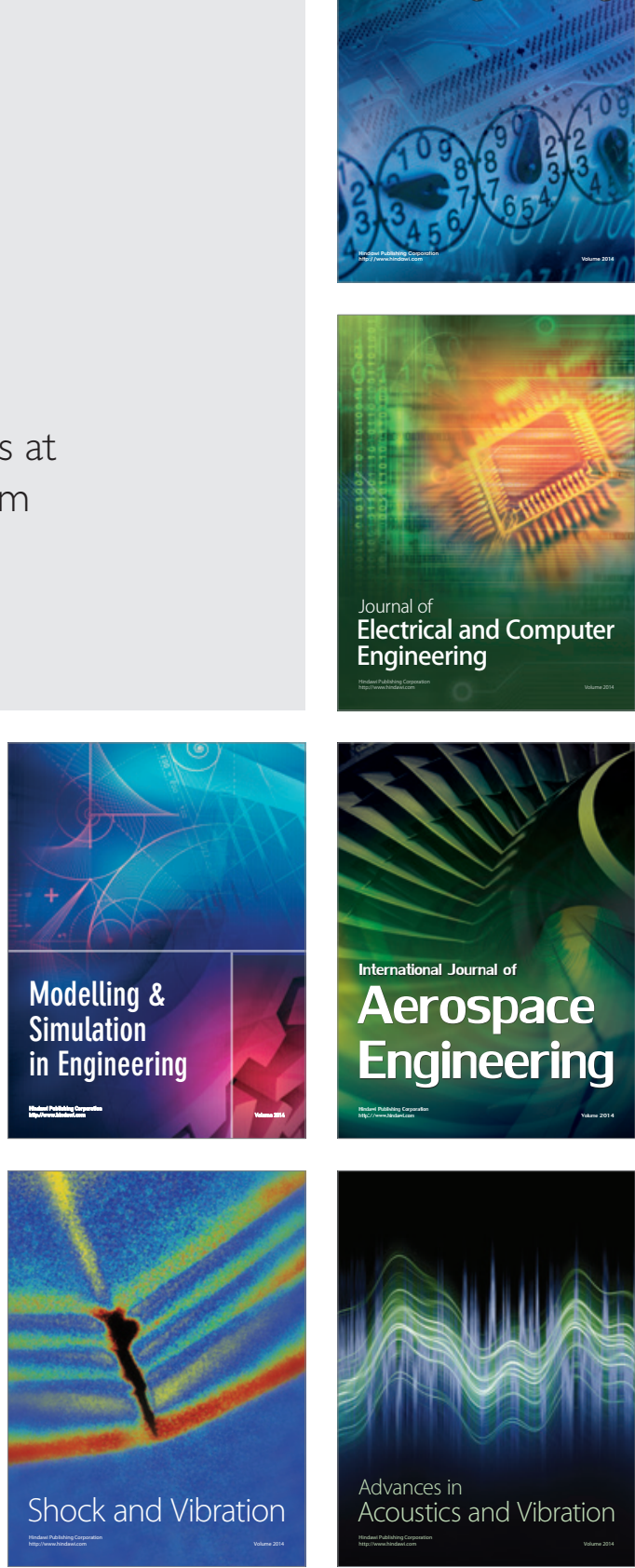